\title{
New species of Haematoloechus (Digenea: Plagiorchidae) in the lung of the foothill yellow-legged frog Rana boylii (Anura), from Humboldt County, California, USA
}

\author{
Especie nueva de Haematoloechus (Digenea: Plagiorchidae) del pulmón de la rana de patas \\ amarillas Rana boylii (Anura), de Humboldt County, California, Estados Unidos de América
}

\author{
David Zamparo ${ }^{1}$, Amanda Ferrao ${ }^{2}$, Daniel R. Brooks ${ }^{1}$, Jamie Bettaso ${ }^{3}$, and Rosario Mata-López ${ }^{4 *}$ \\ ${ }^{I}$ Department of Ecology and Evolutionary Biology, University of Toronto, Toronto, Ontario, Canada M5S 3 G5. \\ ${ }^{2}$ School of Life Sciences, Arizona State University, PO Box 874601, Tempe, AZ 85287-4601. \\ ${ }^{3}$ U.S. Fish and Wildlife Service, Arcata Office, 1655 Heindon Rd, Arcata, CA 95521, USA. \\ ${ }^{4}$ Departamento de Biología Evolutiva, Facultad de Ciencias, Universidad Nacional Autónoma de México, Apartado postal 70-399, 04510, México \\ D.F., México. \\ *Correspondent: gorgoderina@yahoo.com.mx
}

\begin{abstract}
A new species of Haematoloechus is described from the lungs of Rana boylii from Humboldt County, California. The new species is similar to Haematoloechus buttensis, Haematoloechus kernensis, and Haematoloechus complexus in general course of the uterus and gonad shape. It is similar to H. buttensis by having a cirrus sac terminating midway between the posterior margin of the pharynx and the anterior margin of the ovary, and having a smaller oral/ ventral sucker ratio; to $H$. complexus by having the genital pore ventral to the pharynx, and it is similar to $H$. kernensis by having a larger oral sucker to pharynx width ratio. The new species is unique by lacking an extra-cecal longitudinal uterine loop from the hind-body. Molecularly, the new species differs $1.04-1.15 \%$ in partial $28 \mathrm{~S}$ sequence with respect to $H$. complexus, and a monophyletic grouping of these specimens in a phylogenetic analysis of all available sequence data consistent with the species-specific status proposed herein. Evidence is also presented to suggest that specimens identified as H. buttensis in Rana pretiosa from British Columbia, Canada represents a new, but still undescribed species. The importance of conducting biological inventories of helminths, along with continued monitoring of populations, and collections based taxonomy are related.
\end{abstract}

Key words: Platyhelminthes, Digenea, Haematoloechus, anuran, parasites, helminths, taxonomy, California.

\begin{abstract}
Resumen. Una especie nueva de Haematoloechus es descrita de los pulmones de Rana boylii de Humboldt County, California. La especie nueva guarda semejanza con Haematoloechus buttensis, Haematoloechus kernensis, y Haematoloechus complexus en la disposición general del útero y en la forma de las gónadas. Es similar a H. buttensis en que la bolsa del cirro finaliza entre el margen posterior de la faringe y el margen anterior del ovario, y en presentar una relación menor entre la ventosa oral y el acetábulo; a $H$. complexus por tener el poro genital ventral a la faringe, y a H. kernensis por tener una relación mayor del ancho de la ventosa oral contra la faringe. La especie nueva es única por carecer de asas uterinas extracecales longitudinales. Molecularmente, la especie nueva muestra $1.04-1.15 \%$ de diferencia en secuencias parciales de $28 \mathrm{~S}$ con respecto $H$. complexus; esta información complementa las diferencias morfológicas. También se presenta evidencia para sugerir que ejemplares identificados como H. buttensis de Rana pretiosa en British Columbia, Canadá probablemente representan una especie nueva aún no descrita. Se aborda la importancia de la realización de inventarios biológicos de helmintos, el monitoreo continuo de las poblaciones y las colecciones basadas en la taxonomía.
\end{abstract}

Palabras clave: Platyhelminthes, Digenea, Haematoloechus, anuros, parásitos, helmintos, taxonomía, California.

\section{Introduction}

During a course of a survey of parasites of vertebrates in California, Unites States, specimens of Rana boylii were found to be infected by an undescribed species of

Recibido: 04 febrero 2009; aceptado: 04 octubre 2010 the lung fluke Haematoloechus Looss, 1899. Despite the high number of the described Haematoloechus species (Prudhoe and Bray, 1982; León-Règagnon et al., 2001; León-Règagnon and Paredes-Calderón, 2002), its traditional morphological characterization has been controversial due to the variability within species (Prokopic and Krivanec, 1974; Kennedy, 1980a, 1980b) resulting in various taxonomic schemes, as subgenera or new genera to accommodate them. Kennedy (1980a) 
concluded that the degree to which the gonads are lobed was affected, in some instances, by ontogeny and deemed an 'unreliable' character; while sucker ratios, the extent of the uterine extracecal longitudinal loop, and position of the testes were 'most reliable' for species determination. Kennedy (1981) on the basis of this study and geographic variability in the widespread species $H$. longiplexus and H. breviplexus (Kennedy, 1980b), revised the genus, zealously lumping North American taxa into just 6 species. Haematoloechus buttensis, $H$. floedae, $H$. parviplexus, $H$. similiplexus, and $H$. breviplexus were all considered as junior synonyms of $H$. varioplexus. León-Règagnon et al. (1999) asserted that is a bit risky to synonymize many species based only on the morphological characteristics of adult worms. Later, León-Règagnon and Brooks (2003) proposed a phylogenetic analysis of the North American species of the genus, validating as species the Kennedy's synonyms, and demonstrated $H$. floedae is a valid and separate species from $H$. breviplexus, $H$. varioplexus and H. parviplexus, through the use of COI and $28 \mathrm{~S}$ sequence data, and identified oral sucker: pharynx ratio, oral sucker: ventral sucker ratio, gonad shape, and extension of vitelline follicles (in fully developed worms) as invariable morphological characters useful for species determination. More recently, Bolek and Janovy (2007) differentiated $H$. complexus, $H$. coloradensis, $H$. longiplexus, and $H$. parviplexus based on metacercariae survival patterns and their distribution in second intermediate hosts; in the same study, these authors recognized $H$. parviplexus as valid species from $H$. varioplexus based on a reevaluation of their morphological characters.

We present herein, a description of a new species of Haematoloechus on the basis of a few valid morphological characters, that is, to which no evidence exists which should discredit their a priori use (cf. Kennedy, 1980a) and tested through potential falsification and corroborated through independent testing (cf. León-Règagnon et al., 2005). We further point out other characters that seem to consistently co-vary with other characters (cf. morphospecies concept) and identified as critically lacking in this group (León-Règagnon and Brooks, 2003).

\section{Materials and methods}

Eighteen foothill yellow-legged frogs, $R$. boylii, were collected from Sandy Bar, 4 miles southeast of Willow Creek, Humboldt Co., California in August of 2006 and in August of 2007. Hosts were euthanized in MS-222 solution. All helminths were collected alive from recently euthanized hosts and placed in distilled water to induce shedding of eggs and examined while alive at that time. Ten Haematoloechus specimens were recovered. For molecular work, 4 worms were preserved directly in absolute ethanol; for morphology, 6 helminths were later fixed by shaking in hot $10 \%$ formalin solution, and stored in $70 \%$ ethanol. These later specimens were stained with Mayer's haematoxylin, dehydrated, cleared in methyl salicylate, and mounted in Canada balsam for identification and deposited at the United States National Parasite Collection (USNPC) in Beltsville, Maryland. Series of values stated in the description refer to the range of the measurements with the mean value in parentheses. All measurements are in micrometers unless otherwise stated. All figures were made with the aid of a drawing tube. Host specimens were collected by David Zamparo, Peter Watts, and Jamie Bettaso under permit 801306-02. Comparisons to Haematoloechus complexus were made from specimens obtained in L. clamitans from Brampton, Ontario, Canada (USNPC 102153, 1 specimen; Colección Nacional de Helmintos CNHE-5640, 3 specimens; and specimens in Rana blairi from Nebraska (USNPC-102183). For molecular work, worms were digested individually with proteinase $\mathrm{K}(25 \mathrm{mg} / \mathrm{ml})$ in $500 \mathrm{ml} \mathrm{STE}$ buffer, $75 \mathrm{ml}$ $10 \% \mathrm{SDS}$, and incubated for $24 \mathrm{~h}$ at $55^{\circ} \mathrm{C}$. Standard phenol extraction method was used to recover total DNA. Laboratory protocols followed those described by Hillis et al. (1996) and Palumbi (1996). Polymerase chain reaction (PCR) was used for amplifying the 5' end of the 28S ribosomal RNA gene and partial COI mitochondrial gene. Amplification and sequencing were performed using forward primer 28Sy 5, CTA ACC AGG ATT CCC TCA GTA ACG GCG AGT 3' and reverse primer 28Sz 5' AGA CTC CTT GGT CCG TGT TTC AAG AC 3' (Palumbi 1996); and COIF 5' TTT TTT GGG GAT CCT GAG GTT TAT 3' (forward) and COIR 5' TAA AGA AAG AAC ATA ATG AAA ATG-3' (reverse). Amplification programs consisted of $1 \mathrm{~min}$ at $94^{\circ} \mathrm{C}$ followed by 35 cycles of $30 \mathrm{sec}$ at $92^{\circ} \mathrm{C}, 30 \mathrm{sec}$ at $50^{\circ} \mathrm{C}$, and $1 \mathrm{~min}$ at $72^{\circ} \mathrm{C}$; followed by $4 \mathrm{~min}$ at $72^{\circ} \mathrm{C}$ for final elongation for the $28 \mathrm{~S}$ gene; and $5 \mathrm{~min}$ at $95^{\circ} \mathrm{C}$ followed by 35 cycles of $30 \mathrm{sec}$ at $95^{\circ} \mathrm{C}, 45 \mathrm{sec}$ at $50^{\circ} \mathrm{C}$, and $1.5 \mathrm{~min}$ at $72^{\circ} \mathrm{C}$, followed by $10 \mathrm{~min}$ at $72^{\circ} \mathrm{C}$ for final elongation for the COI gene. The purified PCR products were sequenced directly on an ABI PRISM 310TM automated DNA sequencer (Applied Biosystems) using the Big Dye Terminator ${ }^{\mathrm{TM}}$ chemistry according to manufacturer's protocols. Sequences were checked, edited and assembled using the computer program Bioedit, version 7.0.9.0 (Hall, 1999). Uncorrected distance matrices were obtained for the pairs of examined sequences, and phylogenetic trees were constructed using PAUP 4.0b10 (Swofford, 2002). Unweighted parsimony analyses using a branch-and-bound search were performed considering character states as unordered, and gaps as 
missing data for separate and combined matrices. In each case, a nonparametric Bootstrap and Jacknife with 1000 replicates, as well as Decay indices, were calculated to evaluate the stability of branches in the resulting topologies. GenBank accession numbers of available sequences of Haematoloechus spp. used for comparison were: for $28 \mathrm{~S}-$ AF151916, AF184251, AF387797, AF387798, AF387801, AF479652, AF479653, AF531857, AF531859, AF531860, AF531861, AF531863, AF531866, AF532138; for ITS15.8S-TS2 -AF133186, AF133187, AF133189, AF133191, AF133196, AF316153, AF316154, AF316155, AF316157, AF316160, AF316161, AF316163; and for COI-AY672116, AY672117, AY672122, AY672123, AY672124, AY672125.

\section{Description}

\section{Haematoloechus humboldtensis n. sp. (Figs. 1-4)}

Description (based on 6 mature specimens): Body elongate, 5.64-6.68 (6.16) mm long, 1.24-1.66 (1.42) wide at mid-hindbody. Tegument spinose; spines 19-25 maximum length. Oral sucker subterminal, round, 460516 (493) long, 452-535 (489) wide. Pharynx 290-354 (327) long by $303-354$ (320) wide, $63-67 \%$ (66\%) of oral sucker width. Glandular or neural cells surrounding anterior and posterior margins of pharynx. Genital pore at mid-level of pharynx, opening ventral. Esophagus very short, 65-120 (90) long. Ceca terminating blindly near posterior extremity. Forebody $29-37 \%$ (33\%) total body length (TBL). Ventral sucker muscular, round 346419 (374) in diameter. Sucker's width ratio 1: 0.72-0.78 (1: 0.76 ). Testes 2 , round to slightly irregular, tandem to oblique with as much as $50 \%$ overlap. Anterior testis 47-48\% TBL from hindend, 645-1048 (785) long by 484725 (610) wide. Posterior testis 758-1130 (905) long by 597-774 (667) wide. Cirrus sac obscured by ascending uterus, $1.05-1.13 \mathrm{~mm}$ long, posterior end terminating anterior to ventral sucker, midway between posterior margin of ventral sucker and pharynx. Ovary immediately posterior to ventral sucker, 56-62\% (60\%) TBL from hindend, sinistral or dextral to midline, 452-485 (465) long by 290-323 (306) wide. Mehlis' gland, medial to ovary. Seminal receptacle ventrally overlapping Mehlis' gland. Laurer's canal not observed. Oviduct short, opens posteriorly from ovary, opens into an öotype at mid-level of ovary, seminal receptacle and common vitelline duct open dorsally into öotype. Uterus proceeds anteriorly to anterior margin of ovary before proceeding posteriorly to hindend, transversely oriented loops, side to side filling dorsal hindbody, no extracecal longitudinal loop before ascending, passing between testes, anteriorly and posteriorly oriented extracecal longitudinal loops lateral to testes, uterus never ventral or dorsal to testes. Metraterm weakly developed, 320-380 long, lateral to mid-line of body, on opposite side of ovary. Vitellarium follicular, in clustered groups, lateral and dorsal to ceca, more than 12 follicles per cluster, 2-3 medial groups in forebody, 0-2 medial groups in hindend posterior to testes on opposite side of ovary, 6-8 total sinistral vitelline groups when ovary is sinistral, 10 when ovary is dextral; 9-10 total dextral vitelline groups when ovary is sinistral, 7-8 when ovary is dextral. Eggs $35-41$ by 18-21. Excretory bladder I-shaped, excretory pore terminal, opens dorsally.

\section{Taxonomic summary}

Type host: Rana boylii Baird, 1854 (Anura: Ranidae).

Type locality: Sandy Bar, 4 miles southeast of Willow Creek, Humboldt Co., California ( $40^{\circ} 52^{\prime} 81^{\prime \prime}$ N; $123^{\circ} 36^{\prime}$ 55 ” W). Elevation 680 feet.

Site of infection: lungs.

Prevalence and intensity: $(4 / 18=22 \% ; 1,4,6,>4)$. Specimens deposited: holotype: USNP 102124. Paratypes: USNP 102125.

Etymology: the species is named after the county of the type locality.

\section{Remarks}

The new species is most similar to Haematoloechus buttensis, Haematoloechus kernensis, and Haematoloechus complexus in general course of the uterus and gonad shape. Of these species, it is most similar to H. buttensis, and differs from both $H$. complexus and $H$. kernensis, by having a shorter cirrus sac terminating no more than the mid distance between the genital pore and ovary (and not reaching the ventral sucker); and having a smaller oral: ventral sucker ratio (1: 0.71-0.78 vs. $1: 0.8-0.84$ and $1: 1$, respectively), among species of Haematoloechus this interval is minimal, but invariable enough to differentiate them. The new species is similar to H. complexus, and differs from both $H$. kernensis and $H$. buttensis, by having the genital pore ventral and not posterior to the pharynx. Ingles (1936:80) described the genital pore as "at level of posterior part of pharynx" in H. buttensis, but that does not agree with his only 2 known specimens, which are on the pharynx. The new species is similar to H. kernensis, and differs from both $H$. complexus and $H$. buttensis, by having a larger oral sucker to pharynx width ratio (1: 0.63 - 

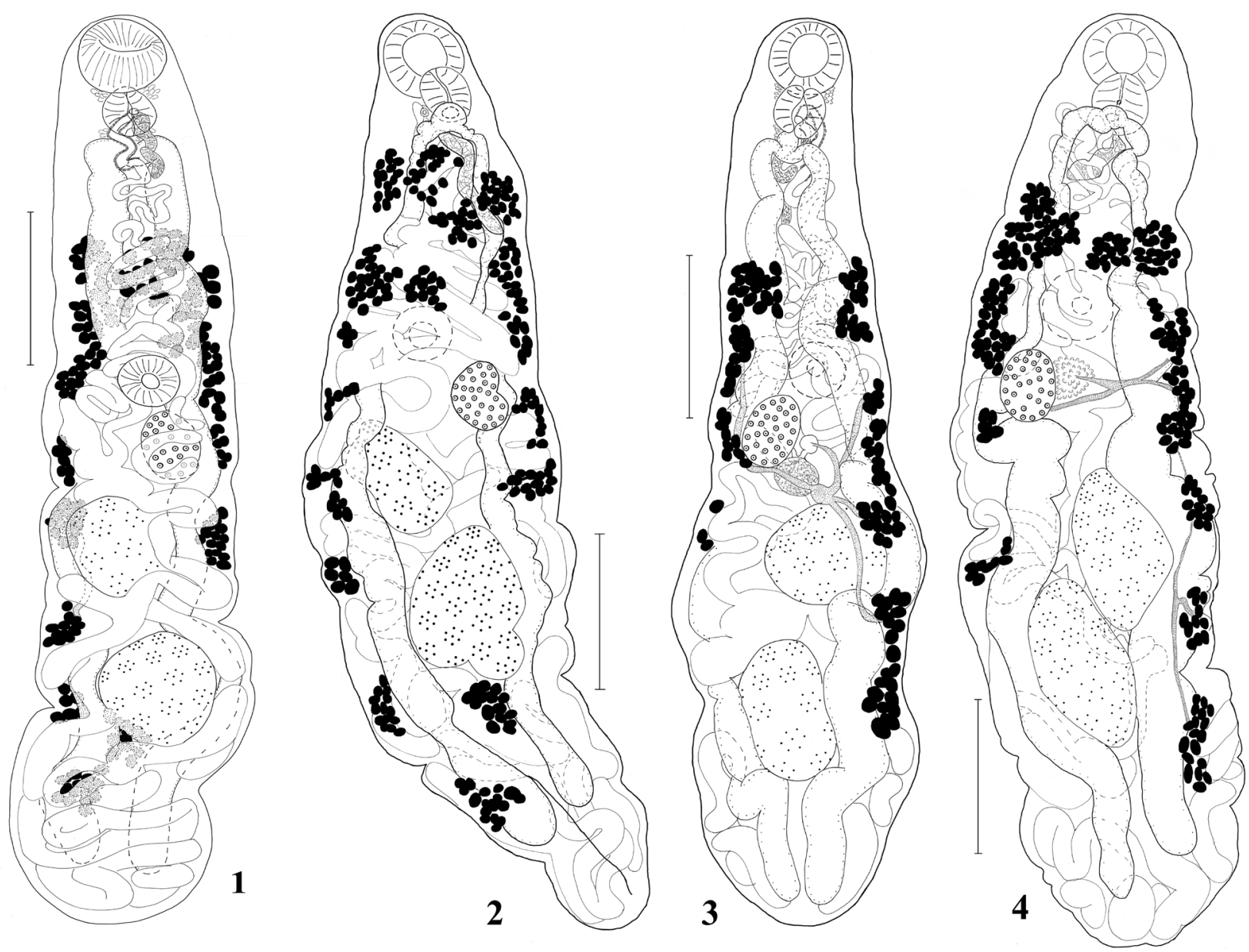

Figures 1-4. Haematoloechus humboldtensis n. sp. 1. Whole mount of type specimen in ventral view, scale bar= $1 \mathrm{~mm} .2$ and 4.2 of 5 voucher specimens demonstrating morphological variability in vitellarium, gonad shape and position, scale bars=1mm. 3. A paratype specimen in dorsal view, scale bar $=1 \mathrm{~mm}$.

0.68 vs $1:<0.61$ and $1:<0.55$ respectively). The new species further differs from $H$. buttensis, but more closely resembles both $H$. kernensis and $H$. complexus, by having an esophagus shorter than the length of the pharynx and is unique by lacking an extra-cecal longitudinal uterine loop from the hind-body. Although molecular data have convincingly demonstrated that presence/absence of extracecal uterine loops are not a phylogenetically informative (Snyder and Tkach, 2001; León-Règagnon and Brooks, 2003), can be used as a diagnostic character.

Partial fragments of $28 \mathrm{~S}$ sequence, $876 \mathrm{bp}$ in length (including the D1 variable domain), and of COI sequence, $361 \mathrm{bp}$ in length, were amplified. Sequences of $H$. humboldtensis $\mathrm{n}$. $\mathrm{sp}$. isolates from the same individual host from the type locality differ from 0 to $0.23 \%$ and from 0.28 to $1.11 \%$ for $28 \mathrm{~S}$, and COI, respectively. The new species differs molecularly from its most morphologically similar species, $H$. complexus, and from $H$. pulcher by only $1.04-1.15 \%$ for $28 \mathrm{~S}$. In the remainder species $(H$. abbreviatus, $H$. danbrooksi, H. floedae, $H$. illimis, $H$. longiplexus, $H$. medioplexus, $H$. parviplexus, $H$. variegatus and $H$. varioplexus) the difference varies between 4.29 and $9.18 \%$. Minimum and maximum divergence values of COI sequences were $12.74 \%$ and $17.18 \%$ between $H$. humboltensis and $H$. danbrooksi and H. longiplexus, respectively. Unfortunately, at present there are not COI sequences available of $H$. complexus for comparison with the new species. Separate phylogenetic analyses for each region and a combined analysis were performed using $H$. longiplexus as outgroup. For both regions, the relationships among sequences of Haematoloechus spp. included in the present study were identical to that topology obtained by 
León-Règagnon and Brooks (2003) for American species of this genus. Three and 6 most parsimonious trees were obtained from separately parsimony analyses with a Branch-and-Bound search for 28S and COI matrices (170 steps long, CI 0.824, RI 0.957, RC 0.788; and 170 steps long, CI 0.688 , RI 0.849 and RC 0.584 , respectively). Thirty six most parsimonious trees resulted from a combined sequence analysis (345 steps long, CI 0.745 , RI 0.915 and RC 0.682); the strict consensus is shown in Figure 5. Supported by high BT, JN (more than $85 \%$ ) and Bremer values, sequences of $H$. humboldtensis appear as monophyletic group in a polytomy with $H$. complexus and H. pulcher. Genbank accession numbers of new species: 28S: GU191156, GU191157, GU191158, GU191159; COI: GU191160, GU191161, GU191162, GU191163.

\section{Discussion}

With each newly described species, there should be greater breadth and depth of comparison, leading to new character descriptions. It is critical that character states be examined, and reported, in historically older taxa in light of improved knowledge in morphology, systematics, genomics and biogeography. This is the primary role of the type series of specimens in biology. However, voucher specimens also serve a vital role as indicators of natural variation, temporal and spatial distribution patterns, particularly in the context of recent rapid environmental changes and biodiversity loses (Hoberg, 2002). For example, Ingles (1936) described a new species, Haematoloechus buttensis, in the foothill yellow-legged frog, Rana boylii Baird, 1854, from Chico Creek, Butte County, California. Ingles (1936) made specific comparisons in differentiating his species to every species but he did not made any comparison with $H$. complexus (Seely, 1906), to which it most closely resembles. The description is lacking in several key characters, and we have discovered that the illustration is not of the type and only available specimen (USNPC 8926) (Fig. 6). Kennedy (1980a) omitted any reference to the genital pore position, and terminal genitalia of specimens he identified as $H$. buttensis, characters that are now identified as crucial for specific identification. Furthermore, the larger oral sucker to pharynx width ratio (1: 0.71$)$, smaller oral to ventral sucker ratio (1: 0.38$)$, host, and geographic locality make us doubt his identification. The ratios most closely resemble those reported for Haematolechus danbrooksi León-Règagnon and Paredes-Calderón, 2002, but the uterine pattern suggests that Kennedy's worms identified as $H$. buttensis may in fact represents yet another new species.

Moreover, sequence data are not available for either H. kernensis or H. buttensis which limits the scope

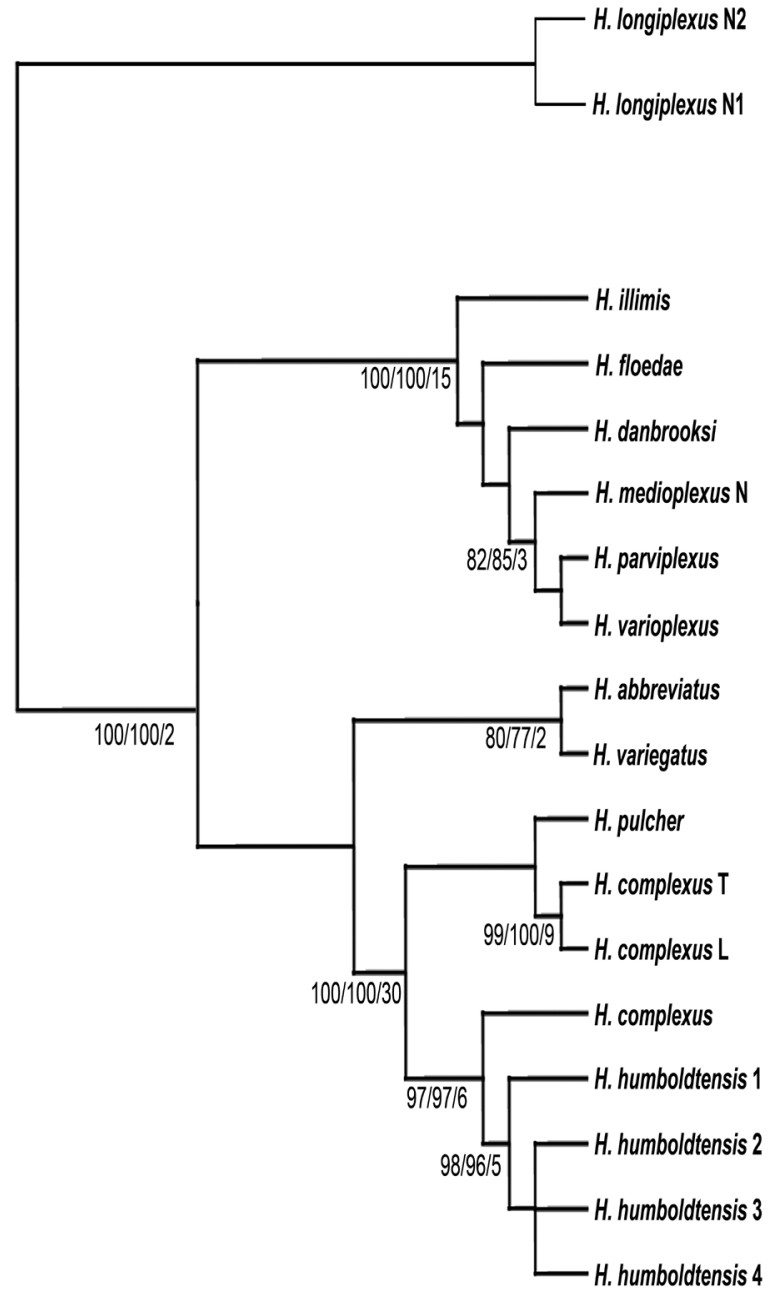

Figure 5. Strict consensus of 36 most parsimonious trees (Length 345, CI 0.745, RI 0.915, RC 0.682) obtained from a combined analysis of the partial sequences of $28 \mathrm{~S}$ and COI of Haematoloechus spp. Bootstrap, Jacknife (as percentage) and Bremer values shown under each branch.

of our comparisons. However, we are able to include $H$. complexus sequence data, which given our prior morphological analysis, may be the most relevant comparison. Phylogenetic analysis of the available molecular data indicates that our specimens form a monophyletic grouping, most closely related to a paraphyletic $H$. complexus, one clade of which is the sister taxon to $H$. pulcher. Genetic differences between these 3 nominal species (1.04-1.15\% difference with respect to $H$. humboldtensis) support the recognition of our specimens as a new species. Our phylogeny only invalidates (or falsifies) the hypothesis that specimens used herein and identified as H. complexus are a single species. Either, the identification 


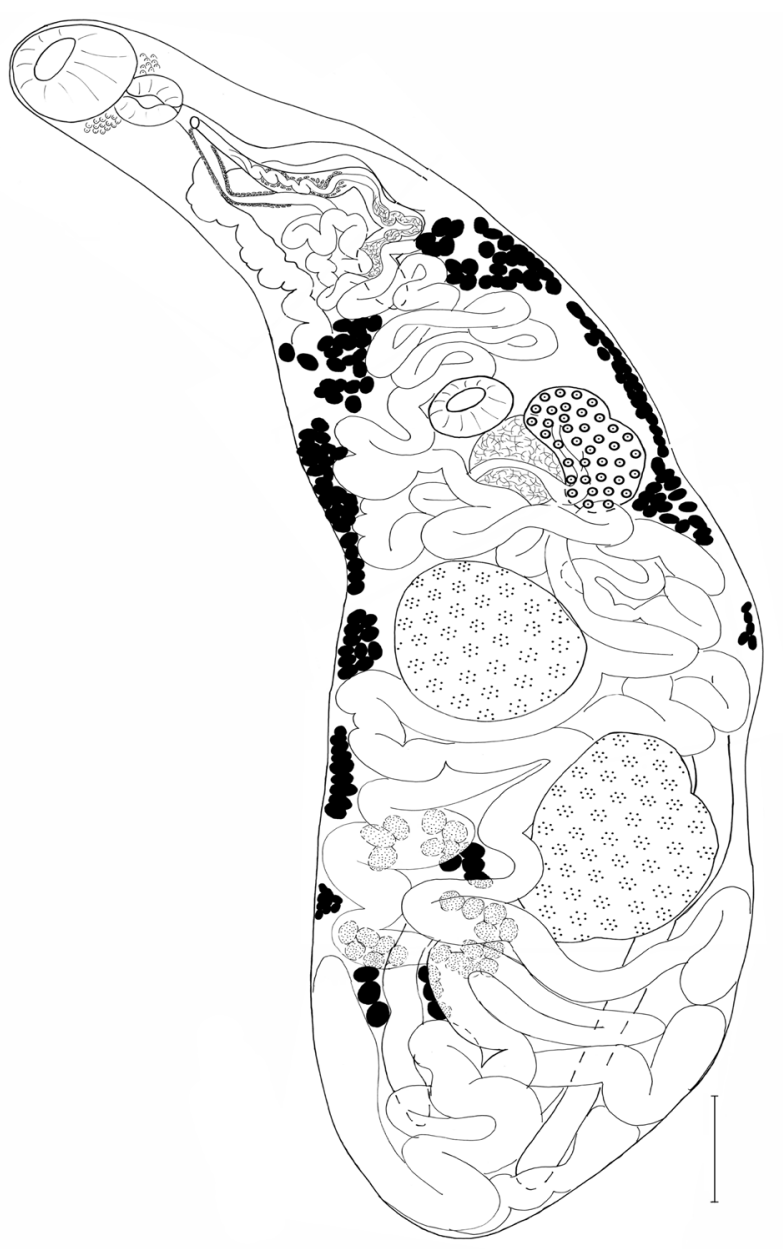

Figure 6. Type specimen of Haematoloechus buttensis (USNPC 8926), scale bar $=500$ microns.

of some of those $H$. complexus specimens is wrong or the species is not valid. Without further information, we cannot decide between these 2 alternatives at present. Undoubtedly, issues involving $H$. complexus will require the eventual designation of a type. However, all available data, presented herein, morphological, phylogenetic, and genetic distances, supports the notion that the specimens recovered in the lungs of $R$. boylii from Humboldt County represent a new species.

Parasite populations as studies through spatial analyses (eg. Beta diversity analyses, Bush et al., 2001) are thought to be ephemeral. We are unaware of any actual historical examples of 1 parasite species replacing another at a particular locality as may have occurred in Humboldt County if Walker (1965) was correct and our sampling was unbiased. Recently, Bolek and Janovy (2007) demonstrated that there are many non-odonate intermediary hosts for both $H$. complexus and $H$. coloradensis. If some species of Haematoloechus are generalist at second intermediate host level as suggested by Bolek and Janovy (2007), then seasonal prevalence of those intermediary hosts coupled with host dietary preferences alone may ecologically and temporally segregate different species of Haematoloechus. The third possibility is that Walker (1965) misidentified his specimens, and was in fact dealing with specimens identified herein as a new species. Whether there has been a parasitic faunal change during the past 40 years, will never be known because voucher specimens were never deposited. The history of taxonomy is replete with examples of the lack of type specimens leading to taxonomic confusion, and retarding progress toward much needed conceptually richer process knowledge (see Hoberg, 2002). History also demonstrates that the fates of personal collections are unpredictable as their value to universities for teaching purposes is at best fleeting.

Specimens are the most efficient form of retaining information content, providing historical biodiversity baselines. The work presented herein, explicitly demonstrates the importance of depositing voucher specimens in permanent collections which are more than mere repositories of information but rather form the basis of comparative research programs (Hoberg, 2002). Taxonomy and systematics as a sciences require testability. If species are real, and if species are important, their identification as biologically fundamental units requires cycles of discovery and evaluation (Brooks and McLennan, 2002; Hoberg, 2006).

\section{Acknowledgments}

We would like to thank the U.S. Fish and Wildlife Service, Arcata Office for their assistance and exceptional service; faculty and students of Humboldt State for their hospitality, helpful discussions and comments on the work presented herein. Special thanks to Dr. Peter Watts, for outstanding assistance in the field. We also thank Dr. Eric P. Hoberg (Chief Curator) and Pat Pilitt (Associate Curator) of the United States Parasite Collection, U. S. Department of Agriculture, Agricultural Research Service, Beltsville, Maryland for their exceptional service, and years of personal support and encouragement. Molecular work was performed at the Laboratory of Molecular Systematics of the Royal Ontario Museum, Ontario, Canada. Thanks to V. León-Règagnon for her valuable comments to this manuscript. Funding was received, in part, through the Barcoding of Life Project, via Dr. Paul Hebert at Guelph University; and Natural Sciences and Engineering Research Council (NSERC) to Dr. Daniel R. Brooks at the University of Toronto. RML thanks Daniel $\mathrm{R}$. Brooks for the facilities provided within the Department 
of Ecology and Evolutionary Biology, University of Toronto during her postdoctoral position. This study was also partially funded by Dirección General de Asuntos del Personal Académico DGAPA, UNAM in form of PROFIP postdoctoral scholarship to RML.

\section{Literature cited}

Bolek, M. G. and J. Janovy Jr. 2007. Evolutionary avenues for and constraints on the transmission of frog lung flukes (Haematoloechus spp.) in dragonfly second intermediate hosts. Journal of Parasitology 93:593-607.

Brooks, D. R. and D. A. McLennan. 2002. Nature of Diversity: an evolutionary voyage of discovery. University of Chicago Press. 668 p.

Bush, A. O., J. C. Fernández, G. W. Esch and J. R. Seed. 2001. Parasitism: The diversity and ecology of animal parasites. Cambridge University Press. 566 p.

Hall, T. A. 1999. BioEdit: a user-friendly biological sequence alignment editor and analysis program for Windows 95/98/ NT. Nucleic Acids Symposium, Serie 41:95-98.

Hillis, D. M., B. K. Mable and C. Moritz. 1996. Nucleic acids IV: Sequencing and cloning. In Molecular Systematics, D. M. Hillis, C. Moritz and B. K. Mable (eds.). Sinauer, Sunderland, Massachusetts. p. 321-383.

Hoberg, E. P. 2002. Foundations for an Integrative Parasitology: Collections, Archives, and Biodiversity Informatics. Comparative Parasitology 69:124-131.

Hoberg, E. P. 2006. Phylogeny of Taenia: species definitions and origins of human parasites. Parasitology International 55:S23-S30

Ingles, L. G. 1936. Worm parasites of California amphibia. Transactions of the American Microscopical Society 55:73-92.

Kennedy, M. J. 1980a. Host-induced variations in Haematoloechus buttensis (Trematoda: Haematoloechidae). Canadian Journal of Zoology 58:427-442.

Kennedy, M. J. 1980b. Geographical variation in some representatives of Haematoloechus Looss, 1899 (Trematoda: Haematoloechidae) from Canada and the United States. Canadian Journal of Zoology 58:1151-1167.

Kennedy, M. J. 1981. A revision of species of the genus
Haematoloechus Looss, 1899 (Trematoda: Haematoloechidae) from Canada and the United States. Canadian Journal of Zoology 59:1836-1846.

León-Règagnon, V., D. R. Brooks and G. Pérez-Ponce de León. 1999. Differentiation of Mexican species of Haematoloechus Looss, 1899 (Digenea: Plagiorchiformes): Molecular and morphological evidence. Journal of Parasitology 85:935-946.

León-Règagnon, V., D. R. Brooks and D. A. Zelmer. 2001. Morphological and molecular description of Haematoloechus meridionalis n. $\quad$ sp. (Digenea: Plagiorchioidea: Haematoloechidae) from Rana vaillanti Brocchi of Guanacaste, Costa Rica. Journal of Parasitology 87:1423-1427.

León-Règagnon, V. and D. R. Brooks. 2003. Molecular Phylogeny of Haematoloechus Looss, 1899 (Digenea: Plagiorchiidae), with Emphasis on North American Species. Journal of Parasitology 89:1206-1211.

León-Règagnon, V. and L. E. Paredes-Calderón. 2002. Haematoloechus danbrooksi n. sp. (Digenea: Plagiorchioidea), from Rana vaillanti of Los Tuxtlas, Veracruz, Mexico. Journal of Parasitology 88:1215-1221.

León-Règagnon, V., S. Guillen-Hernández and M. A. ArizmendiEspinosa. 2005. Intraspecific variation of Haematoloechus floedae Harwood, 1932 (Digenea: Plagiorchiidae), from Rana spp. in North and Central America Journal of Parasitology 91:915-921.

Palumbi, S. R. 1996. Nucleic acids II. The polymerase chain reaction. In Molecular Systematics, D. Hillis, C. Moritz and B. K. Mable (eds.). Sunderland, Massachusetts: Sinauer, p. 205-247.

Prokopic, J. and K. Krivanec. 1974. Trematodes of the genus Haematoloechus Looss, and their variability. Helminthologia 15:779-802.

Prudhoe, S. and A. Bray. 1982. Platyhelminth Parasites of the Amphibia. London. British Museum (Natural History) and Oxford University Press, 217 p.

Seely, L. B. B. 1906. Two distomes. Biological Bulletin 10:249-254.

Swofford, D. L. 2002. PAUP* Phylogenetic analysis using parsimony (and other methods) Version 4. Sinauer Associates, Sunderland, Massachusetts.

Walker, M. E. 1965. A survey of helminth parasites of Rana boyei $[\mathrm{sic}]$ from Humboldt County, California. M.A. Thesis. Humboldt State College. 34 p. 
